\title{
XI. On the union of gases
}

\section{James Scholes}

To cite this article: James Scholes (1808) XI. On the union of gases, Philosophical Magazine Series 1, 31:121, 68-70, DOI: 10.1080/14786440808563850

To link to this article: http://dx.doi.org/10.1080/14786440808563850

$$
\text { 曲 Published online: } 18 \text { May } 2009 .
$$

Submit your article to this journal 전

III Article views: 2

Q View related articles $₫$ 
with the silver, as usually practised in the manufacture of that metal. Having, however, uniformly observed the green light, from the purest silver leaf I could obtain, when deflagrated either by an electrical or Voltaic battery, I did not. feel inclined to assent to this conclusion without further trial; and was rather disposed to attribute the phænomena then observed to some other cause. The construction of a large Voltaic apparatus for the Lectures at the Scientific Institution, soon afforded me an opportunity of verifying the opinion I had formed. Having observed that Mr. Davy's conducting wires were terminated by charcoal, I employed a similar arrangement; and applying the charcoal to pure silver leaf, it immediately burned with a beautiful white light. Some of the same portion of silver having been before employed, when the green flame was produced, it became evident that the white light in this and in Mr. Davy's experiment proceeded from the charcoal : and that this was really the case, appeared from the immediate evolution of green light when the contact was made by a metallic wire. By the application of charcoal to the extremity of a wire, so bent that either the wire or charcoal may touch the silver at pleasure, the white and the green flame may be alternately produced; and a conclusive demonstration of the fact, with a pleasing variation of a brilliant experiment, will be thus at once afforded.

\section{On the Union of Gases.}

To $M r$. Tilloch.

SIR,

I have sent you the inclosed for a place in your work, if you think fit. An idea has struck me of a mechanical union of gas, which will not be liable to any of the objections raised against Mr. Dalton's, and which, I believe, will apply to every phænomenon. The principle is this, that from the laws of elastic fluids, it will be found to follow, that if the particles of one be larger than the particles of another; or rather, if the repulsive sphere of one be greater than the re- 
pulsive sphere of ancther, the particles of any two (or more) elastic fluids will arrange themselves at the greatest possible distance from each other. This, I think, would bear issue with mathematical demonstration, which is what Mr. Dalton evidently shrinks from:-but I am almost satiated with hypotheses, there are such shallow ones, and in vogue too:-we need no more of them, till those we already have be more justly appreciated.

I remain your obedient humble servant,

JAMES SChOLES.

Manchester,

June 24, 1808.

In Mr. Dalton's new Treatise on Chemical Philosophy just published, it appears to me, he assumes this principle, That two gases, each pressing on the containing vessel, with a force as $1 \cdot$ from every particle, and having no repulsive action on each other, the joint effect of this pressure will be equal to the individual effect of a single gas with a similar pressure of 1.26 ; which cannot be the case. For suppose $a$, a repulsive force that has the power of extending a certain quantity of gas $\mathrm{A}$, under a given pressure, a certain space $s$; and suppose $b$ another repulsive force that has the power of extending another quantity of another gas $B$, under the same pressure, the same space $s$;-neither of these two forces can extend these gases to greater space than $s$ (the contrary is absurd). And these two gases will conjointly, if put together on these principles, only occupy the same space $s$, that each would individually. But the repulsive power of gases under the same circumstances is as the space occupied : consequent$\mathrm{ly}$, the powers of expansion in two gases with no repulsive action on each other, cannot act conjointly, but must be equal only to the expansion of a single gas whose power is as great as either of these supposed conjoined forces; and, as it has been generally inferred, two measures of gas combined on this theory ought only to occupy the space of one before admixture. Mr. Dalton admits, that if an equal quantity of two gases be combined according to his principles, in one vessel, the repulsion of their particles from each other, being 1.26 before admixture, will afterward's become only $1 \cdot:$ but, says 
he, the pressure upon the vessel will still be the same as before. But $I$ have endeavoured to show that nothing can be derived from a supposed conjoint action of the repulsion of the gases. From whence, therefore, must half the pressure proceed? The number of particles is the same hefore and after admixture: there is in one case $n$ particles pressing upon the vessel with a force $=1 \cdot 26$; and in the other $n$ particles pressing with a force $=1$. only:-How can the aggregate of these forces be equal? And again, for every action there must be a corresponding reaction: the particles of a gas, therefore, cannot press upon a vessel in a greater degree than they react upon themselves. And as Mr. Dalton supposes that gases under this combination have nothing to react upon but particles of their own species, How can he reconcile the pressure upon the vessel as being 1.26 for each particle of gas, whilst he himself supposes the utmost reaction of each particle as $1 \cdot$ only?

XII. Report of Surgical Cases in the City and Finsury Dispensuries, for December 1807. By John TaunToN, Esq.

$I_{N}$ the month of December there were admitted on the books of the City and Finsbury Dispensaries 228 surgical patients.

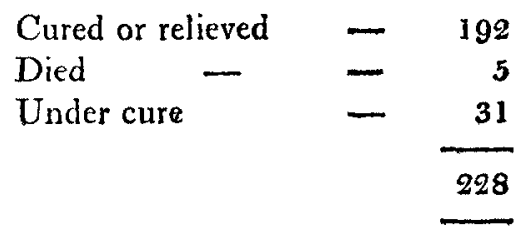

Since which time there have been admitted 1283 .

Miss R., æt. 26, of a spare habit of body, delicate constitution, general health much impaired, suffers greatly during the discharge of the catamenia, which returns at intervals of about six or seven weeks.

About six years since she received a blow on the right breast, which produced a general swelling of the gland, attended with much pain : these were relieved by fomentations 